\title{
Periodic sub-wavelength structures with large phase retardation fabricated by glass nanoimprint
}

\author{
Toshiharu MORI, ${ }^{\dagger}$ Naoto YAMASHITA, ${ }^{*}$ Haruya KASA, ${ }^{* *}$ Kohei FUKUMI, ${ }^{* *}$ Kenji KINTAKA ${ }^{* *}$ \\ and Junji NISHII**
}

Konica Minolta Opto, Inc., 4-18, Takadai, Itami, Hyogo 664-8577

*Isuzu Glass Co., Ltd., 6-3-6, Minamitsumori, Nishinari-ku, Osaka 557-0063

**National Institute of Advanced Industrial Science and Technology, 1-8-31, Midorigaoka, Ikeda, Osaka 563-8577

\begin{abstract}
One-dimensional periodic sub-wavelength structures (SWSs) with a period of $300 \mathrm{~nm}$ were fabricated on a bismuth germanoborate glass plate by a direct glass nanoimprint method using $\mathrm{SiC}$ molds. The borate glass had a refractive index of 1.82 at $587.6 \mathrm{~nm}$ wavelength, an internal transmittance higher than $80 \%$ at a thickness of $3 \mathrm{~mm}$ in the visible wavelength region, and a deformation temperature of $468^{\circ} \mathrm{C}$. SWSs with height of a few hundred nanometers were simultaneously fabricated on both surfaces of the glass plate by the glass nanoimprint at $488^{\circ} \mathrm{C}$ for $120 \mathrm{~s}$ with $8 \mathrm{MPa}$ in pressure. The SWSs showed form birefringence. A phase retardation of $0.23 \lambda$ was observed between transverse electric (TE)- and transverse magnetic (TM)-polarized beams at $400 \mathrm{~nm}$ wavelength.
\end{abstract}

(C)2009 The Ceramic Society of Japan. All rights reserved.

Key-words : Periodic sub-wavelength structure, Phase retardation, Glass nanoimprint, Form birefringence, Grating, Borate glass

[Received May 28, 2009; Accepted August 20, 2009]

\section{Introduction}

Periodic sub-wavelength structures (SWSs) have been attracting much attention as key elements for the realization of several optical functions such as antireflection, ${ }^{1), 2)}$ polarization-independent diffraction, ${ }^{3)}$ polarization splitting, ${ }^{4)}$ isolation, ${ }^{5)}$ and phase control. ${ }^{6-8)}$ The conventional fabrication process of these SWSs is electron-beam (EB) lithography followed by dry etching. Recently, the nanoimprint process has been investigated as a promising technology for reduction of the fabrication cost and time of SWSs. Several research groups have reported the fabrication of SWSs on resin plates or films using ultraviolet-imprinting or thermal-imprinting processes. ${ }^{8)-10)}$ However, the mechanical strength and the long-term chemical durability of the resin are sometimes insufficient for practical use as high-quality optical devices. Inorganic glasses have mechanical strength, chemical durability and thermal stability higher than resins, and therefore, the fabrication of SWSs on glass surfaces has been attempted by the nanoimprint process. ${ }^{11-17)}$

In a previous study, one-dimensional (1D) periodic SWS with a period of $300 \mathrm{~nm}$ and a groove depth of $210 \mathrm{~nm}$ was fabricated on a glass surface by the nanoimprint process, which exhibited a phase retardation of $0.08 \lambda$ at a wavelength of $400 \mathrm{~nm}$ between transverse electric (TE)- and transverse magnetic (TM)- polarized beams due to form birefringence. ${ }^{16), 17)}$ Higher phase retardation is, however, required for the application of $1 \mathrm{D}$ periodic SWS to quarter wavelength plate. Higher phase retardation can be attained by the use of materials with a higher refractive index and/or by the fabrication of higher-aspect-ratio (deeper groove) structure. It is, however, still difficult to fabricate high-aspectratio structure on glass surfaces by the nanoimprint process. One

Corresponding author: T. Mori; E-mail: toshiharu.mori@ konicaminolta.jp of the solutions to overcome this difficulty is the fabrication of SWSs on both surfaces of a glass plate, which doubles the phase retardation. In the present study, a borate glass with a high refractive index and low deformation temperature has been developed. A 1D-SWS with $300 \mathrm{~nm}$ period has been fabricated on both surfaces of the glass.

\section{Introduction experimental procedures}

\subsection{Preparation of glass for nanoimprint}

Glasses used in the present study must have a low deformation temperature for glass nanoimprint, a high refractive index for form birefringence and high transmittance in the near ultraviolet ray region for the application to several optical appliances such as Blu-ray disc drives. It is expected that $\mathrm{Bi}_{2} \mathrm{O}_{3}-\mathrm{GeO}_{2}-\mathrm{B}_{2} \mathrm{O}_{3}$ glass fulfills the properties required in the present study, since it is known that $\mathrm{Bi}_{2} \mathrm{O}_{3}-\mathrm{B}_{2} \mathrm{O}_{3}$ glasses have a high refractive index and low deformation temperature ${ }^{18)}$ and it is expected from the optical basicity that the addition of $\mathrm{GeO}_{2}$ to $\mathrm{Bi}_{2} \mathrm{O}_{3}-\mathrm{B}_{2} \mathrm{O}_{3}$ glass improves the transmittance in the near ultraviolet ray region. ${ }^{19)}$ Therefore, the glass formation and properties of glass were studied in $\mathrm{Bi}_{2} \mathrm{O}_{3}-\mathrm{GeO}_{2}-\mathrm{B}_{2} \mathrm{O}_{3}$ system, particularly, in the composition of $(40-0.5 y) \mathrm{Bi}_{2} \mathrm{O}_{3} \cdot y \mathrm{GeO}_{2} \cdot(60-0.5 y) \mathrm{B}_{2} \mathrm{O}_{3}$ along the compositional line between $40 \mathrm{Bi}_{2} \mathrm{O}_{3} \cdot 60 \mathrm{~B}_{2} \mathrm{O}_{3}$ and $80 \mathrm{GeO}_{2} \cdot 20 \mathrm{~B}_{2} \mathrm{O}_{3}$. The glass used for the glass nanoimprint was sought around this compositional line.

The mixture of reagent grade of $\mathrm{Bi}_{2} \mathrm{O}_{3}, \mathrm{GeO}_{2}$ and $\mathrm{B}_{2} \mathrm{O}_{3}$ was melted in a Pt crucible at temperatures from 1000 to $1200^{\circ} \mathrm{C}$ in air, and was poured onto a carbon plate to form a $50 \mathrm{~g}$ glass. The glass formation was confirmed by the naked eye. The thermal expansion coefficient was measured with a thermo-mechanical analyzer (Seiko Instrument Inc., TMA/SS6300) under a load of $0.1 \mathrm{~N}$ using samples with $10 \mathrm{~mm}$ length. Refractive indexes were measured at 404.7 (Hg-h line), 435.8 (Hg-g line), 546.1 (Hg-e line), 587.6 (He-d line), and $656.3 \mathrm{~nm}$ (H-C line) with a precision 
refractometer (Shimadzu Co., KPR-2000) and at 632.8 (He-Ne laser) and 831.8 (semiconductor laser) $\mathrm{nm}$ with a prism coupling instrument (Metricon, prism coupler Model 2010). Optical absorption spectra were measured with a spectrophotometer (Hitachi, Ltd., U4000 spectrophotometer).

\subsection{Fabrication of one-dimensional periodic struc- tures in $\mathrm{SiC}$ molds}

SiC plates of $25 \times 25 \times 2 \mathrm{~mm}$ with an optically flat surface (YW; Adomap, Inc.) were used for the molds, since it has been reported that $\mathrm{SiC}$ has heat-resistance and a high mechanical strength and also has micro-workability. ${ }^{20)} \mathrm{A}$ W-Si film with 120 $\mathrm{nm}$ thickness was deposited by DC sputtering and an EB resist (ZEP520A; Zeon Co.) was spin-coated on the SiC plates. Then, a grating pattern with $300 \mathrm{~nm}$ period and $150 \mathrm{~nm}$ grating width was drawn with an EB direct writing apparatus (ELS-7500EX; Elionics, Inc.) on the $\mathrm{SiC}$ plates in $6 \times 6 \mathrm{~mm}$ area, followed by the development of resist with o-xylene. The grating pattern was transferred to the $\mathrm{W}-\mathrm{Si}$ mask layer by inductively coupled plasma reactive ion etching (ICP-RIE, RIE-200iP; Samco, Inc.) with $\mathrm{SF}_{6}$ gas. The $\mathrm{SiC}$ plate was etched through the patterned $\mathrm{W}-$ Si mask by ICP-RIE with a gas mixture of $\mathrm{CHF}_{3}$ and $\mathrm{O}_{2}{ }^{21)}$ The $\mathrm{SiC}$ plates with one-dimensional periodic grooves obtained were used as molds for the glass nanoimprint.

\subsection{Glass nanoimprint}

Glass nanoimprint was carried out using a pressing machine (GMP-311V; Toshiba Machine Co., Ltd.). The two SiC plates with one dimensional periodic grooves were set as the upper and lower molds in the pressing machine. The grooves of the upper and lower $\mathrm{SiC}$ molds were parallel to each other. A glass preform of $12 \mathrm{~mm}$ diameter and $2 \mathrm{~mm}$ thickness was set between the $\mathrm{SiC}$ molds. In this study, the imprinting temperature, pressure, and time were $488^{\circ} \mathrm{C}, 8 \mathrm{MPa}$, and $120 \mathrm{~s}$, respectively. Adhesion between the $\mathrm{SiC}$ molds and the glass occurred during glassimprinting at a temperature beyond $488^{\circ} \mathrm{C}$, pressure beyond 8 $\mathrm{MPa}$, and time longer than $120 \mathrm{~s}$. Before imprinting, the pressing chamber was filled with $\mathrm{N}_{2}$ gas and subsequently evacuated to pressures lower than $0.4 \mathrm{~Pa}$ in order to minimize the residual $\mathrm{O}_{2}$ gas. The upper mold was removed from the glass after pressing at an elevated temperature and the glass was removed from the lower mold after cooling. The surface of the glass was observed with a scanning electron microscope (Hitachi, Ltd., S-4800) and an atomic force microscope (Shimadzu, Co., SFT-3500).

\subsection{Phase retardation measurement}

The phase retardation between TE- and TM-polarized beams transmitted through the one-dimensional periodic structures was measured with a rotating analyzer (RETS-100; Otsuka Electronics Co., Ltd.).

\section{Results and discussion}

\section{$3.1 \mathrm{Bi}_{2} \mathrm{O}_{3}-\mathrm{GeO}_{2}-\mathrm{B}_{2} \mathrm{O}_{3}$ glass}

Deformation temperature, refractive index at $587.6 \mathrm{~nm}$, internal transmittance ( $3 \mathrm{~mm}$ thick) at $400 \mathrm{~nm}$ wavelength of the (40$0.5 y) \mathrm{Bi}_{2} \mathrm{O}_{3} \cdot y \mathrm{GeO}_{2} \cdot(60-0.5 y) \mathrm{B}_{2} \mathrm{O}_{3}$ glasses were plotted against the $\mathrm{GeO}_{2}$ content in Fig. 1. Glass was formed in the region from $y=0$ to 55 . Glass was partially devitrified at $y=60$. The deformation temperature showed a maximum at $40 \mathrm{~mol}_{\%} \mathrm{GeO}_{2}$. Such an anomaly have been reported in the $\mathrm{Bi}_{2} \mathrm{O}_{3}-\mathrm{B}_{2} \mathrm{O}_{3}$ and $\mathrm{Bi}_{2} \mathrm{O}_{3}-$ $\mathrm{GeO}_{2}$ glass systems. ${ }^{22), 23)}$ The refractive index decreased gradually with the $\mathrm{GeO}_{2}$ content, but was higher than 1.7. The internal transmittance at $400 \mathrm{~nm}$ wavelength increased with the $\mathrm{GeO}_{2}$ content. Based on these experiments, we chose $17.5 \mathrm{Bi}_{2} \mathrm{O}_{3}$. $50 \mathrm{GeO}_{2} \cdot 32.5 \mathrm{~B}_{2} \mathrm{O}_{3}$ glass for the following glass nanoimprint process. That is, $\mathrm{Bi}_{2} \mathrm{O}_{3}$ was substituted for $\mathrm{B}_{2} \mathrm{O}_{3}$ by $2.5 \mathrm{~mol} \%$ for $15 \mathrm{Bi}_{2} \mathrm{O}_{3} \cdot 50 \mathrm{GeO}_{2} \cdot 35 \mathrm{~B}_{2} \mathrm{O}_{3}$ glass to increase the refractive index to higher than 1.8 with maintaining the deformation temperature lower than $470^{\circ} \mathrm{C}$ and the internal transmittance higher than $80 \%$. Properties of this glass are summarized in Table 1. The glass had a refractive index of 1.82 at $587.6 \mathrm{~nm}$ wavelength, an internal transmittance higher than $80 \%$ (3 mm thickness) at a wavelength of $400 \mathrm{~nm}$, and a deformation temperature of $468^{\circ} \mathrm{C}$.

\subsection{Glass nanoimprint}

Figure 2 shows a scanning electron microscope (SEM) photograph and an atomic force microscopic (AFM) depth profile of grooves of the one-dimensional periodic structure fabricated on the $\mathrm{SiC}$ molds. The period and groove depth of grooves fabricated on $\mathrm{SiC}$ were 300 and $220 \mathrm{~nm}$, respectively, according to the AFM measurement. The cross-sectional groove structure was not

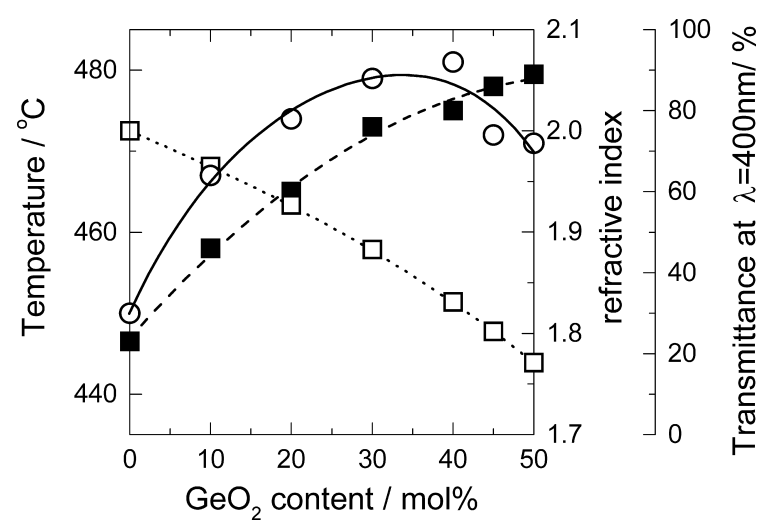

Fig. 1. Deformation temperature, refractive index at $587.6 \mathrm{~nm}$ wavelength and internal transmittance at $400 \mathrm{~nm}$ wavelength $(3 \mathrm{~mm}$ thickness) against $\mathrm{GeO}_{2}$ content $(\mathrm{mol} \%)$. Open circles, open squares and closed squares represent deformation temperature, refractive index and transmittance, respectively. Curves are shown for the guide of eyes.

Table 1. Properties of $17.5 \mathrm{Bi}_{2} \mathrm{O}_{3} \cdot 50 \mathrm{GeO}_{2} \cdot 32.5 \mathrm{~B}_{2} \mathrm{O}_{3}$ Glass

\begin{tabular}{ccccccccccc}
\hline$T g$ & $\begin{array}{c}A t \\
{ }^{\circ} \mathrm{C}\end{array}$ & $\begin{array}{c}\alpha \\
10^{-7} \mathrm{~K}^{-1}\end{array}$ & $n_{\mathrm{h}}$ & $n_{\mathrm{g}}$ & $n_{\mathrm{e}}$ & $n_{\mathrm{d}}$ & $n_{633}$ & $n_{\mathrm{C}}$ & $n_{832}$ & $\begin{array}{c}\tau_{400} \\
\%\end{array}$ \\
\hline 425 & 468 & 75.7 & 1.846 & 1.839 & 1.823 & 1.816 & 1.811 & 1.807 & 1.795 & 85
\end{tabular}

$\overline{T g}, A t, \alpha$ and $\tau_{400}$ represent glass transition temperature, deformation temperature, average linear thermal expansion coefficient $\left(30-400^{\circ} \mathrm{C}\right)$ and internal transmittance at $400 \mathrm{~nm}$ ( $3 \mathrm{~mm}$ thickness ), respectively. $n_{\mathrm{h}}, n_{\mathrm{g}}, n_{\mathrm{e}}, n_{\mathrm{d}}, n_{633}, n_{\mathrm{C}}$, $n_{832}$ represent refractive indexes at $404.7,435.8,546.1,587.6,632.8,656.3$ and $831.8 \mathrm{~nm}$, respectively.
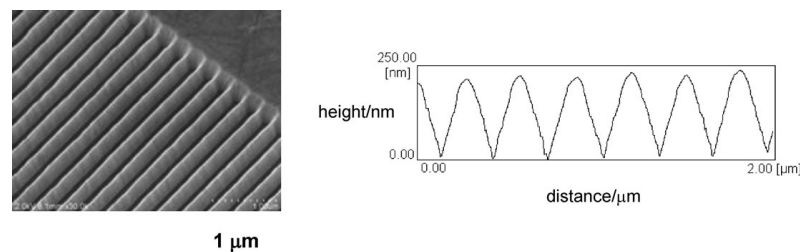

(a)

(b)

Fig. 2. (a) SEM photograph and (b) AFM depth profile of grooves of $\mathrm{SiC}$ mold surface. 


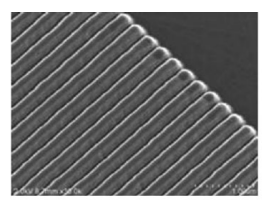

$1 \mu \mathrm{m}$

(a)

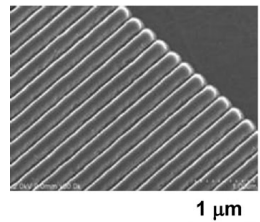

(c)

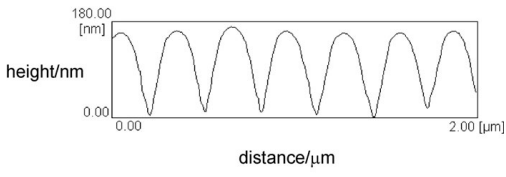

(b)

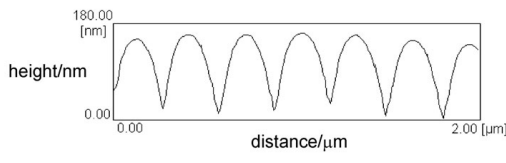

(d)
Fig. 3. SEM photographs of (a) upper and (c) lower surfaces, and AFM height profiles of (b) upper and (d) lower surfaces of glass after glass nanoimprinting.

rectangular in shape but a tapered shape, which was suitable to fabricate high-aspect-ratio structures by the glass nanoimprint. ${ }^{24)}$

Figure 3 shows the SEM photographs and the AFM height profiles of the upper and lower glass surfaces after imprinting. It can be seen that one-dimensional periodic structures were formed on both the upper and lower surfaces of the glass. It was confirmed by the SEM observation that the structures were formed in the area of $6 \times 6 \mathrm{~mm}$ on both sides of the glass. Since the glass was removed from the lower mold after cooling in the present study, the mismatch of the thermal expansion coefficient between the glass and mold $\left(43 \times 10^{-7} \mathrm{~K}^{-125}\right)$ below the glass transition temperature should cause the shrinkage difference of about $1.2 \mu \mathrm{m}$ at the end of the periodic structure, which is greater than the period of the structure. However, the glass was removed from the lower mold without breakage of the structure. It is unclear yet why the structure was not broken during cooling. We speculated that the tapered shape of grooves caused the selfdemolding of glass during cooling, which prevented the structure from breaking.

The grating heights of the upper and lower surfaces were 170 and $150 \mathrm{~nm}$, respectively, according to the AFM measurement. The grating height on the glass was lower than that of the groove depth of the SiC mold. Further improvement of imprinting conditions is currently underway to realize the greater grating height.

\subsection{Phase retardation of the glass}

Figure 4 shows the relationship between the phase retardation obtained empirically and the wavelength. The phase retardation of $0.23 \lambda$ was obtained at $400 \mathrm{~nm}$ wavelength. The phase retardation expected for a model structure was calculated numerically using commercially available software (GSOLVER 4.20: Grating Solver Development Co.) based on a rigorous coupled wave analysis. ${ }^{26)}$ The model had rectangular cross-sectional grooves, a line/space ratio of 1:1, and grating heights of 170 and $150 \mathrm{~nm}$ on each surface. The calculated values, as shown by solid squares in Fig. 4, agree fairly well with the experimental values, showing that the phase retardation observed in the present study was due to form birefringence. The small difference between the experimental and calculated values might be due to the difference between the model structure and fabricated structure. Finally, it

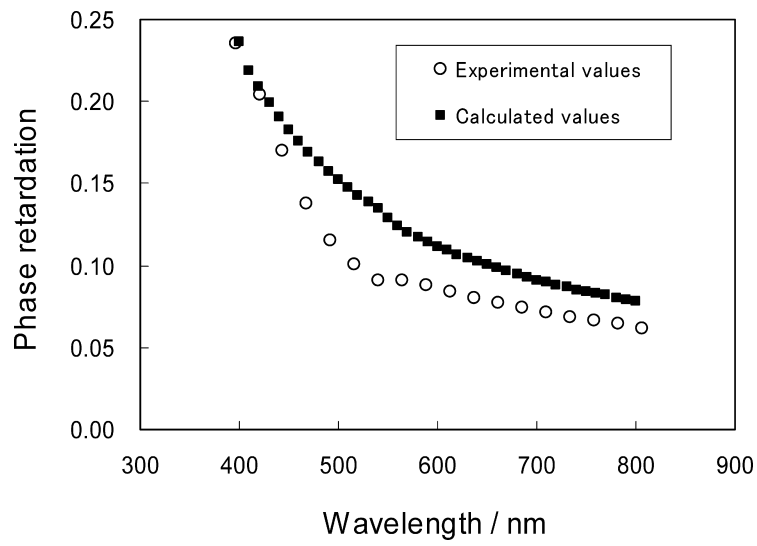

Fig. 4. Relationship between wavelength and phase retardation between TE-polarized and TM-polarized beams transmitted through periodic structures. The open circles and solid squares represent the experimental and the calculated values, respectively.

should be stressed that the quarter wavelength plate is expected to be produced by the glass nanoimprint process.

\section{Conclusion}

One-dimensional periodic sub-wavelength structures were simultaneously fabricated on both sides of a newly developed bismuth germano-borate glass plate by a direct glass nanoimprint method using $\mathrm{SiC}$ molds. The structure with a period of $300 \mathrm{~nm}$ and height of a few hundred nanometers were successfully formed on both sides of the glass surfaces in an area of $6 \times 6$ $\mathrm{mm}$. The glass showed a phase retardation of $0.23 \lambda$ at $400 \mathrm{~nm}$ wavelength, which originated from the form birefringence.

Acknowledgement This work was carried out as a study of Nextgeneration Nanostructured Photonic Device and Process Technology under the Program to Create an Innovative Components Industry supported by New Energy and Industrial Technology Development Organization (NEDO).

\section{References}

1) S. J. Wilson and M. C. Hutley, Optica Acta, 29, 993-1009 (1982).

2) H. Toyota, K. Takahara, M. Okano, T. Yotsuya and H. Kikuta, Jpn. J. Appl. Phys., 40, L747-L749 (2001).

3) J. Nishii, K. Kintaka and T. Nakazawa, Applies Optics, 43, 1327-1330 (2004).

4) B. Wang, C. Zhou, S. Wang and J. Feng, Opt. Lett., 32, 1299 1301 (2007).

5) T. Glaser, S. Schröter, H. Bartelt, H. Fuchs and E. Kley, Applies Optics, 41, 3558-3566 (2002).

6) H. Kikuta, Y. Ohira and K. Iwata, Applies Optics, 36, 15661572 (1997).

7) T. Isano, Y. Kaneda, N. Iwakami, K. Ishizuka and N. Suzuki, Jpn. J. Appl. Phys., 43, 5294-5296 (2004).

8) T. Yoshikawa, T. Konishi, M. Nakajima, H. Kikuta, H. Kawata and Y. Hirai, J. Vac. Sci. Technol., B 23, 2939-2943 (2005).

9) Y. Hirai, S. Yoshida, N. Takagi, Y. Tanaka, H. Yabe, K. Sasaki, H. Sumitani and K. Yamamoto, Jpn. J. Appl. Phys., 42, 3863-3866 (2003).

10) B. Päivänranta, N. Passilly, J. Pietarinen, P. Laakkonen, M. Kuittinen and J. Tervo, Opt. Exp., 16, 16334-16342 (2008).

11) A. Y. Yi, Y. Chen, F. Klocke, G. Pongs, A. Demmer, D. Grewell and A. Benatar, J. Micromech. Microeng., 16, 2000-2005 
(2006).

12) Y. Hirai, K. Kanakugi, T. Yamaguchi, K. Yao, S. Kitagawa and Y. Tanaka, Microelectronic Eng., 67/68, 237-244 (2003).

13) M. Takahashi, K. Sugimoto and R. Maeda, Jpn. J. Appl. Phys., 44, 5600-5605 (2005).

14) H. Takebe, M. Kuwabata, M. Komori, N. Fukugami, M. Soma and T. Kusuura, Opt. Lett., 32, 2750-2752 (2007).

15) M. Yasui, M. Takahashi, S. Kaneko, T. Tsuchida, Y. Hirabayashi, K. Sugimoto, J. Uegaki and R. Maeda, Jpn. J. Appl. Phys., 46, 6378-6381 (2007).

16) T. Mori, K. Hasegawa, T. Hatano, H. Kasa, K. Kintaka and J. Nishii, Opt. Lett., 33, 428-430 (2008).

17) T. Mori, K. Hasegawa, T. Hatano, H. Kasa, K. Kintaka and J. Nishii, Jpn. J. Appl. Phys., 47, 4746-4750 (2008).

18) P. Becker, Cryst. Res. Technol., 38, 74-82 (2003).

19) J. A. Duffy and M. D. Ingram, "Optical properties of glass,"
Ed. by D. R. Uhlmann and N. J. Kreidl, Am. Cram. Soc., Westerville (1991) pp. 159-184.

20) S. W. Pang, T. Tamamura, M. Nakao, A. Ozawa and H. Masuda, J. Vac. Sci. Technol. B, 16, 1145-1149 (1998).

21) K. Yamada, M. Umetani, T. Tamura, Y. Tanaka, H. Kasa and J. Nishii, Appl. Surf. Sci., 255, 4267-4270 (2009).

22) K. Nassau and D. L. Chadwick, J. Am. Ceram. Soc., 65, 197202 (1982).

23) D. Ehrt, Glass Tech., 41, 182-185 (2000).

24) T. Mori, Y. Kimoto, H. Kasa, K. Kintaka, N. Hotou, J. Nishii and Y. Hirai, Jpn. J. Appl. Phys., 46, 06FH20 (2009).

25) "Gmelins Handbuch der Anorganischen Chemie," System No. 15, Silicium [B] New edition, Verlag, Weinheim (1959) pp. 819-822.

26) M. G. Moharam, A. Pommet and E. B. Grann, J. Opt. Soc. Am., 12, 1077-1086 (1995). 